\title{
Structures of Glycolipids Found in Trypanosomatids: Contribution to Parasite Functions
}

\author{
Eliana Barreto-Bergter* and Alane Beatriz Vermelho
}

\author{
Departamento de Microbiologia Geral, Instituto de Microbiologia Prof. Paulo de Góes (IMPPG), Centro de Ciências \\ da Saúde (CCS) Universidade Federal do Rio de Janeiro (UFRJ), Bloco I, Ilha do Fundão, 21941-590 Rio de Janeiro, \\ RJ, Brazil
}

\begin{abstract}
Neutral monohexosylceramides (CMHs) globosides (globotriasyl ceramides), other glycosphingolipids (GSLs) and more complex structures such as glycoinositol-phospholipids(GIPLs) and glycosyl phosphatidylinositol (GPI) anchors have been described in several members of the trypanosomatid family. These highly bioactive molecules are not only components of biological structures but also participants in host-parasite interactions such as macrophage invasion, antigenic presentation and signal transduction. Glycolipid structures have been studied using mass spectrometry (MS).This review describes a wide range of glycoconjugates with unique and complex structures that are present in several trypanosomatid species. Their structures are described in the context of their biological significance.
\end{abstract}

Keywords: Trypanosomatids, GSLs, GIPLs, GPI-anchor proteins, mass spectrometry.

\section{INTRODUCTION}

Glycoconjugates have been studied as components of several members of the trypanosomatidae family. These cellsurface molecules play important roles in parasite survival and infectivity. A wide range of glycoconjugates with different and complex structures are present in several species. Among them, we found lipid- containing carbohydrates (glycolipids) such as glycosphingolipids (GSLs), glycoinositolphospholipids (GIPLs) and glycosylphosphatidyl inositol (GPI-APs) anchors [1].

Fig. (1) shows some of these glycoconjugates on a trypanosomatid plasma membrane.

Glycosphingolipid structures have been characterized from non-pathogenic trypanosomatids such as Trypanosoma mega and a bat trypanosomatid, as well as Trypanosoma cruzi [2-4].

The etiologic agents of tropical and subtropical diseases such as leishmaniasis (Leishmania spp.), African sleeping sickness (Trypanosoma brucei) and Chagas disease (Trypanosoma cruzi) are all members of the family trypanosomatidae and have been the target of extensive research. Many studies have focused on the unusually high levels of GPI-anchored molecules present in these organisms, which are thought to form a dense, homogeneous and protective coat on the parasite cell surface [5]. These molecules include the variant surface glycoprotein (VSG) in the bloodstreamform of T. brucei [6], metalloprotease Gp63 (or leishmanolysin) in Leishmania [7] and (GIPLs) in Leishmania [5].

\footnotetext{
*Address correspondence to this author at the Departamento de Microbiologia Geral, Instituto de Microbiologia Prof. Paulo de Góes (IMPPG), Centro de Ciências da Saúde (CCS) Universidade Federal do Rio de Janeiro (UFRJ), Bloco I, Ilha do Fundão, 21941-590 Rio de Janeiro, RJ, Brazil; Tel: 55(021)25626743; Fax: 55(021)25608344;

E-mail: eliana.bergter@micro.ufrj.br
}

Each parasite stage is already known to have different glycoconjugates $[8,9]$. The aim of this mini-review is to describe the bioactive molecules found in trypanosomatids and correlate them with their biological significance.

\section{GLYCOSPHINGOLIPIDS (GSLs)}

GSLs are membrane components of plant, animal and microbial cells. They are amphiphatic molecules containing mono- or oligosaccharide groups that are glycosidically attached to $\mathrm{C}-1$ of an amino alcohol sphingosine. Complex sphingolipids have a fatty acid attached in an amide linkage (Fig. 2). The fatty acids vary in chain length, degree of unsaturation (most are saturated), and presence or absence of a hydroxyl group.

GSLs have been implicated in many fundamental cellular processes including growth, differentiation and morphogenesis. GSLs modulate cell signaling by controlling the assembly and specific activities of plasma membrane proteins. They are highly bioactive and are involved in many aspects of cell signaling such as cell-cell interaction, cell-substratum interaction and cell-pathogen interaction. GSLs also are involved in the modulation of signal transduction, resulting in regulation of cell proliferation and differentiation $[10,11]$.

Using the carbohydrate moiety as a reference, GSLs can be divided into different classes including cerebrosides (GSLs containing mono- or oligosaccharide groups that are glycosidically attached to C-1 of the amino alcohol sphingosine), sulfatides (sulfate esters of some cerebrosides), globosides (GSLs containing two or more monosaccharide units) and gangliosides (similar to globosides but also containing sialic acid).

In eukaryotic organisms, there is a high diversity of GSL structures. Plants and fungi often contain glycosphingolipids with relatively simple carbohydrate structures, although clear differences in the structure of the ceramide backbone of these organisms are present [12]. Determination of GSL 


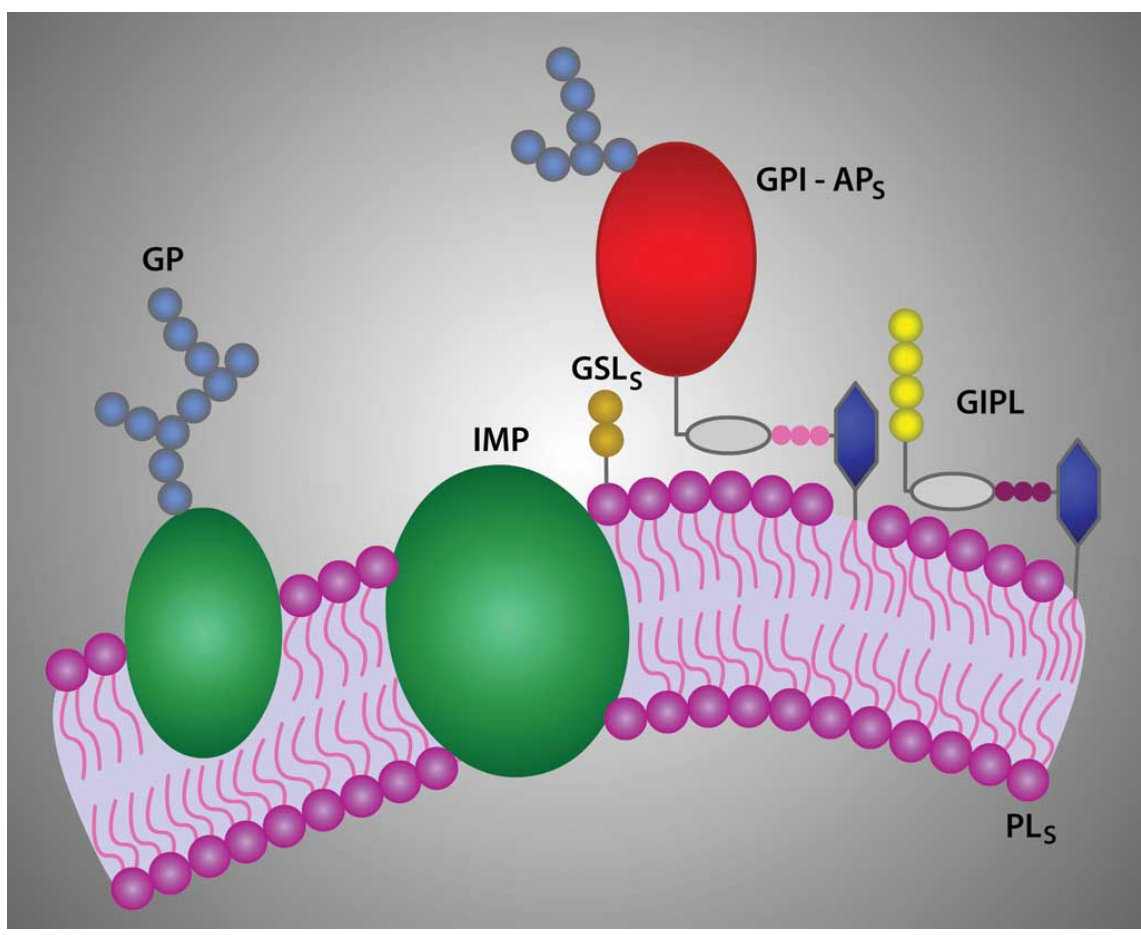

Fig. (1). Membrane glycoconjugates from trypanosomatids. GP, glycoprotein; IMP, integral membrane protein; GSLs, glycosphingolipids; GPI-APs, GPI-anchored proteins; GIPL, glycoinositolphospholipids; and PLs, phospholipids.

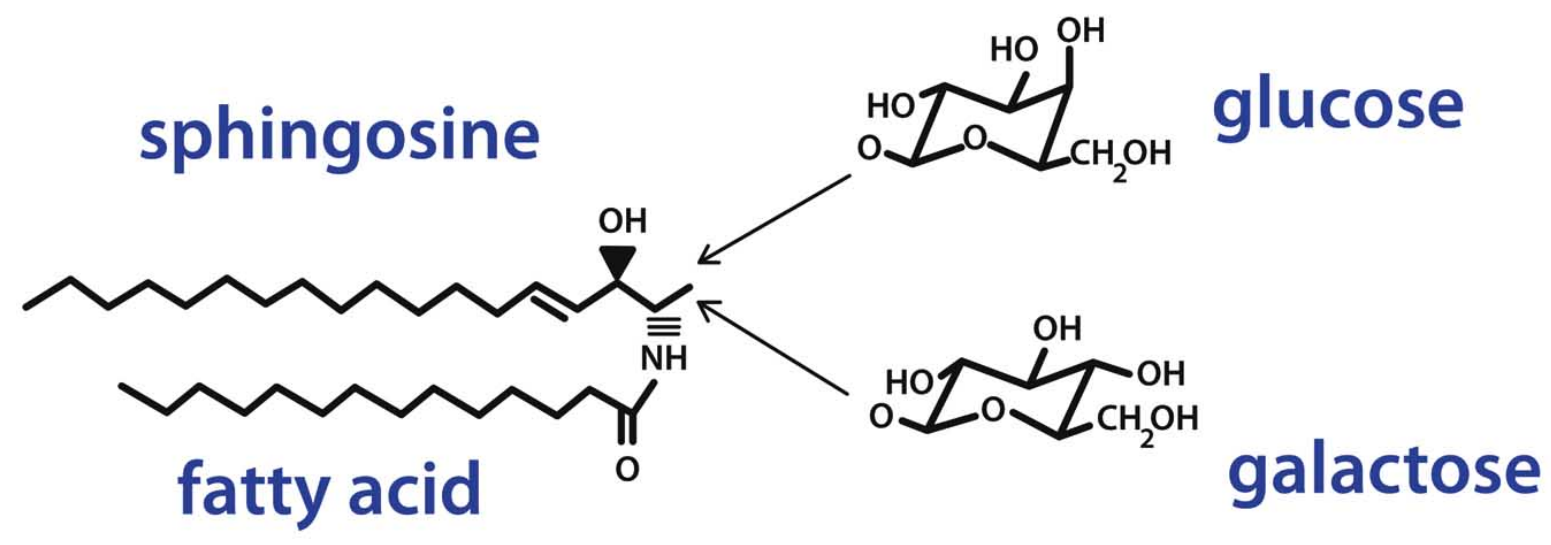

Fig. (2). Structure of a typical glycosphingolipid containing only one monosaccharide (monohexosylceramide) from mammalian cells. The glycolipids have a fatty acid attached in amide linkage to the sphingosine (d18:1) (forming ceramides). The monosaccharide (galactose or glucose) is attached glycosidically to $\mathrm{C}-1$ of sphingosine.

structures is greatly dependent on the use of mass spectrometry (MS), such as fast atom bombardment MS (FAB-MS), electrospray ionization (ESI-MS) and dissociation MS (ESIMS/CID-MS); ${ }^{1} \mathrm{H}$ and ${ }^{13} \mathrm{C}$-Nuclear Magnetic Resonance (NMR) have also been used successfully. A combination of these techniques is usually sufficient for complete structural elucidation [12].

\section{Trypanosoma cruzi}

The major neutral glycosphingolipids from the T. cruzi Y strain were identified as ceramide mono- and dihexosides $(\mathrm{CMH}$ and $\mathrm{CDH})$, and their structures were elucidated using a combination of column chromatography, HPTLC, and gaschromatography (GC) together with FAB-MS and $500 \mathrm{MHz}^{-1}$ $\mathrm{H}-\mathrm{NMR}$ spectroscopy [3]. The molecular species of $\mathrm{CMH}$ contain glucose or galactose, sphingosine (d18:1) and fatty acyl groups that are mainly C-24 saturated, monounsaturated or 2-hydroxy fatty acids (Table 1). The different molecular species can be attributed to $\mathrm{CMH}$ molecules that differ only in the chain length of their hydroxy fatty acids. The ceramide dihexoside was identified as lactosylceramide with sphingosine (d18:1) as the long chain base and 16:0, 18:0, 24:0 and 24:1 fatty acids as the major components. No evidence of hydroxylated fatty acids was obtained by MS [3].

Recently, ceramide species containing C23:0 and C25:0 were also described among GIPLs from T. cruzi [13]. Glucosyl- and lactosylceramides were also isolated and their structures were characterized in another T. cruzi strain, Dm28c. [4] (Fig. 3). 
Table 1. Relative Distribution of Fatty Acid Chain Length Among Ceramide Monohexoside Fractions CMH-C $\mathrm{CH}_{\mathrm{OH}}$ and $\mathrm{CMH}-\mathrm{C}_{\mathrm{n}}$ from T. cruzi (Y Strain) as Calculated from the $[\mathrm{M}+\mathrm{H}-60]^{+}$Ions of the Per-O-acetylated Compounds. CMH-C ${ }_{n}$, Ceramide Monohexosides from T.cruzi with - $n$ Fatty Acids; CMH-C ${ }_{\mathrm{OH}}$, CMH with $\alpha$-hydroxy Fatty Acids from T.cruzi

\begin{tabular}{|c|c|c|c|c|}
\hline$[\mathrm{M}+\mathrm{H}-60]+(\mathrm{m} / \mathbf{z})$ & Chain length of $n$-fatty acid & CMH-Cn (\%) & Chain length of $\alpha$-hydroxy acid & СМН-С \\
\hline 934 & $22: 0$ & 24 & - & - \\
\hline 962 & $24: 0$ & 39 & - & - \\
\hline 1004 & - & - & $23: 0$ & 15 \\
\hline 1006 & - & - & $24: 1$ & 13 \\
\hline 1020 & - & - & $24: 0$ & 33 \\
\hline 1034 & - & - & $25: 0$ & 13 \\
\hline
\end{tabular}

Based on the MS data, only sphingosine is present in the ceramide moiety.

Table 2. Relative Distribution of Fatty Acid Lengths of the Ceramide Dihexoside Fraction of CDH from T. cruzi (Y Strain) as Calculated from the $[\mathrm{M}+\mathrm{H}-60]^{+}$Ions of Per-O-acetylated Species

\begin{tabular}{|c|c|c|}
\hline$[\mathbf{M}+\mathbf{H}-\mathbf{6 0}]+(\mathbf{m} / \mathbf{z})$ & Fatty acid chain length & CDH $(\%)$ \\
\hline \hline 1138 & $16: 0$ & 36 \\
\hline 1166 & $18: 0$ & 35 \\
\hline 1222 & $22: 0$ & 15 \\
\hline 1250 & $24: 0$ & 14 \\
\hline
\end{tabular}

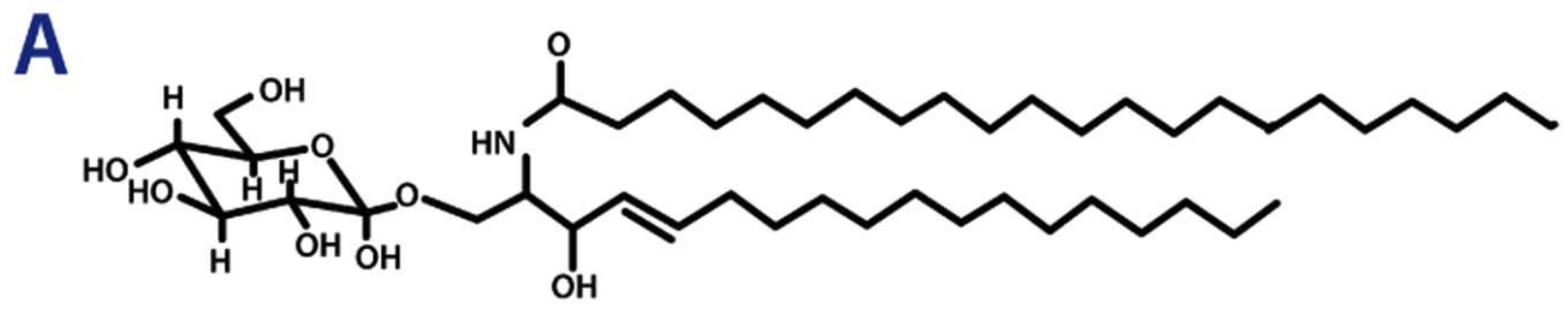

B

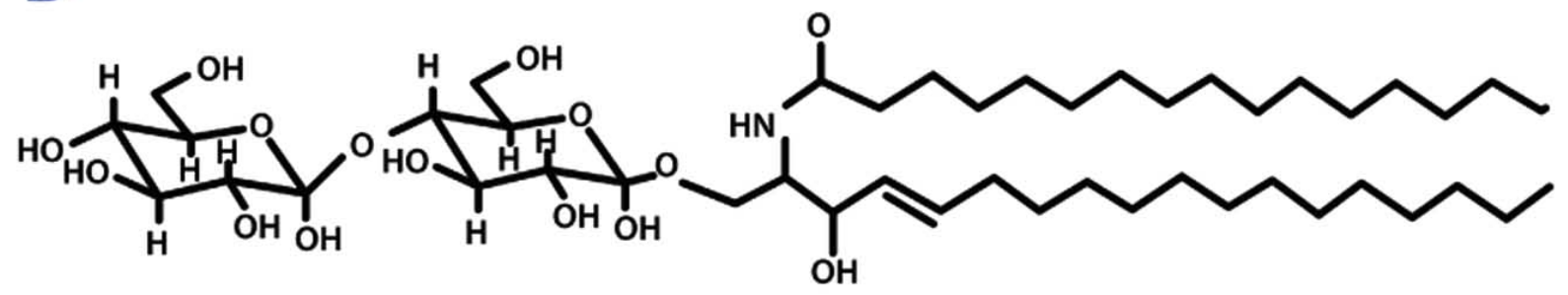

Fig. (3). Main structures of glycosylceramides from clone Dm28c of T.cruzi (A) Glucosylceramide (CMH) and (B) Lactosylceramide (CDH).

The structure of the ceramide monohexoside was elucidated by GC-MS, FAB-MS and ${ }^{1} \mathrm{H}-\mathrm{NMR}$ spectroscopy. Glucose was the only sugar present, and GC-MS analysis of the methanolyzed and trimethylsilylated $\mathrm{CMH}$ revealed three main peaks corresponding to C22:0, C23:0 and C24:0 nonhydroxylated fatty acids. Based on the FAB-MS spectrum and the analytical data for fatty acids, the major molecular species of long-chain base was sphingosine (d18:1), which was represented by an ion at mass to charge ratio $(\mathrm{m} / \mathrm{z}) 264$.

FAB-MS of the per-O-acetylated $\mathrm{CDH}$ fractions gave major molecular ions from $[\mathrm{M}+\mathrm{H}-60]^{+}$at $\mathrm{m} / \mathrm{z} 1223,1237$ 


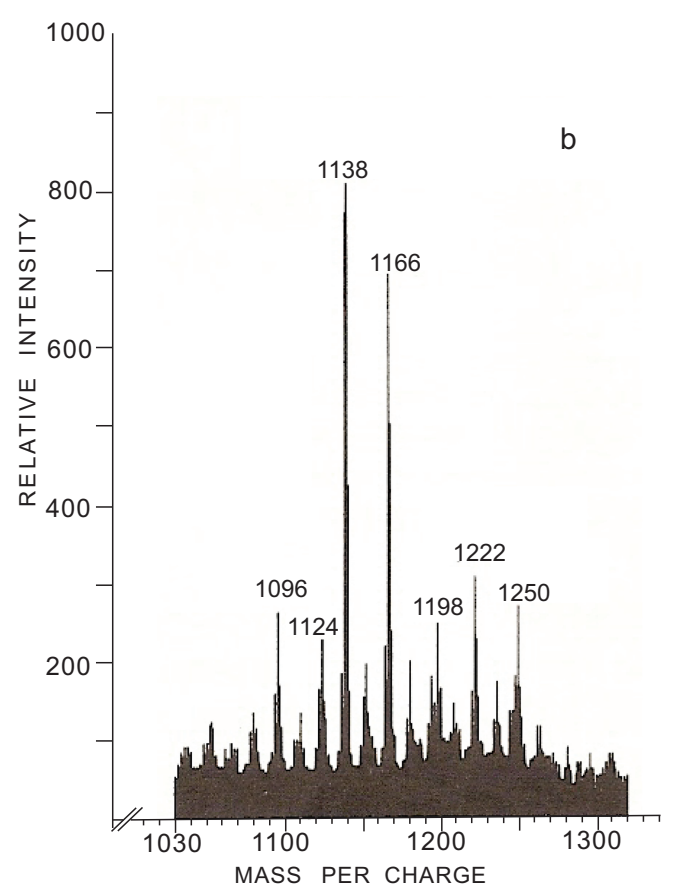

Fig. (4). FAB-MS analysis of the lactosylceramide (LacCer) of clone Dm28c of T. cruzi.

and 1251 (Table 2). The ceramide moiety of CDH was represented by peaks at $\mathrm{m} / \mathrm{z} 646.6(\mathrm{~d} 18: 1 / 22: 0+\mathrm{Ac}), 660.6$ $(\mathrm{d} 18: 1 / 23: 0+\mathrm{Ac})$ and $674.6(\mathrm{~d} 18: 1 / 24: 0+\mathrm{Ac})$. Ions at $\mathrm{m} / \mathrm{z}$ 619,331 and 289 derived from the hexose-hexose group were detected (Fig. 4). The glycan sequence in $\mathrm{CDH}$ was confirmed by enzymatic degradation with $\beta$-galactosidase [4].

These data demonstrate a substantial diversity among $T$. cruzi glycosylceramides. Such differences may be associated with the different courses of Chagas disease observed with different $T$. cruzi clones [14].

GSLs are emerging as attractive targets for antimicrobial therapy [15]. GLS-binding antibodies with potent antimicrobial action have been recently described [12]. It is necessary to characterize the determinants of antigenicity of these molecules, aiming at the identification of antimicrobial antibodies with selective toxicity. Ceramide dihexoside isolated from clone Dm28c of $T$. cruzi was recognized by sera from T. cruzi-immunized rabbits to a much higher extent than the mono-glycosylated form. This result suggests that glycosylation is a determinant of antigenicity in T.cruzi GSL $[4,16]$. Replacement of the ceramide moiety in this GSL by phosphatidylethanolamine resulted in a decrease of serological reactivity, indicating that intramolecular interactions between sugar and ceramide moieties are important for antigenicity. A previously characterized $\mathrm{CMH}$ from the $\mathrm{Y}$ clone of T.cruzi was strongly recognized by immunized sera. These results indicate that fatty acid hydroxylation and ceramide glycosylation influence the serological reactivity of T.cruzi GSL $[4,16]$.

Few studies are currently found in literature concerning the biological role of these molecules in T. cruzi. Cossy-Isasi and collaborators [17] reported that parasite epimastigotes treated with gangliosides from bovine brain presented an altered lipid order that inhibited membrane enzymes and caused morphological alterations. Electron-lucent vacuoles opposite the cytostome, multilamellar bodies and dilated mitochondrion cristae, in addition to a disorganized kinetoplast and altered heterochromatin structure, were found in epimastigote forms $[18,19]$. Trypomastigotes suffered a loss of cytoplasmic material and organelles when the ganglioside GM1 was present in the culture medium. Inoculation of murine models with the ganglioside GM1 has shown a strikingly nonlinear effect leading to a strong decrease in parasite load at low doses but reverting to a load increase at high doses. GM1-treated mice survived and recovered with normal frequency. Cardiomyocyte destruction concomitant with the disease was also significantly reduced by a moderate application of GM1 [18, 19].

\subsection{Trypanosoma mega}

A glycosphingolipid fraction from Trypanosoma mega was isolated and was further purified on a silicic acid column. Preparative thin-layer chromatography was used for final purification. The carbohydrate components of the glycolipid were fucose and galactose in approximately equimolar amounts. The neutral glycolipid of T. mega had a sphingosine base composition that consisted of sphingosine $(\mathrm{d}$ 18:1) and traces of dihydrosphingosine (d 18:0). Fatty acids forming amide groups with the sphingosine bases were analyzed by GC-MS and were a mixture of non-hydroxy and $\alpha$ hydroxy fatty acids. Normal C16:0, C18:0 and 2-hydroxy C18:0 were the predominant fatty acids [2].

\subsection{Leishmania (L) amazonensis}

Glycosphingolipids were characterized in amastigote and promastigote forms of Leishmania (L) amazonensis [20].The structure of the main GSL present in the amastigote forms of this parasite was characterized as $\operatorname{Gal} p \beta(1 \rightarrow 3)$ Galp $\alpha(1 \rightarrow 3)$ $\mathrm{Gal} p \beta(1 \rightarrow 4) \mathrm{Glcp} \beta(1 \rightarrow 1)$ Cer and is referred to as a $\beta$-Galglobotriasylceramide. The role of this glycolipid in macrophage infectivity was confirmed using Mabs directed to this molecule. A putative receptor/lectin of macrophages with a molecular mass of $30 \mathrm{kDa}$ for L.amazonensis GSL was suggested [21].

The specificity of the L.amazonensis interaction could be confirmed by the absence of binding of L.chagasii amastigotes, which do not express the $\beta$-Gal-globotriasylceramide glycoconjugate High concentrations of GSLs as well as sterols were detected in amastigote lipid rafts. Membrane domains were resistant to treatment with non-ionic detergents at $4{ }^{\circ} \mathrm{C}$. Disruption of the membrane microdomains with methyl- $\beta$-cyclodextrin significantly reduced parasite infectivity suggesting a role of GSLs in macrophage invasion by species of Leishmania [19].

Other glycolipids such as IPC and GIPLs, along with sterols, were present in L.amazonensis promastigotes and preferentially distributed in membrane rafts [1].

\section{GLYCOINOSITOLPHOSPHOLIPIDS (GIPLs) AND LIPOPHOSPHOGLYCANS (LPGs)}

The cell surfaces of all trypanosomatids are rich in glycosylphosphatidylinositol (GPI)-anchored proteins and glycans such as lipophosphoglycans (LPG) and other glycoconjugates, which are the free glycoinositol phospholipids 
(GIPLs) that form protective surface coats and mediate essential host-parasite interactions [22-25].

GIPLs may be classified into three types: i) Type-1 GIPLs contain an $\alpha$-Man residue linked $(1 \rightarrow 6)$ to the Man residue of the common motif (Mana1-4GlcNa1-6myoinositol-1- $\mathrm{HPO}_{4^{-}}$) and are abundant in T. cruzi [26], Leishmania donovani and Phytomonas [28, 29], ii) Type-2 GIPLs are defined by the presence of an $\alpha$-Man residue linked $1 \rightarrow 3$ to the Man residue of the common motif and have been described in Leishmania spp. [30, 31], iii) Type-3, the hybrid-type GIPLs, contain the branched structure Man $\alpha 1 \rightarrow 3$ (Man $\alpha 1 \rightarrow 6$ ) Man $\alpha 1 \rightarrow 4$ GlcN $\alpha 1-6 m y o$-inositol-1$\mathrm{HPO}_{4}$-lipid and are found in some Leishmania species [28] and in Herpetomonas samuelpessoai [23]. The addition of oligosaccharide side chains and phosphorylated substituents, as well as distinct types of glycosidic linkages and lipid anchors, are responsible for the diversity of GIPL structures found in trypanosomatids [22,32].

\subsection{Trypanosoma cruzi}

The first free GIPL, called lipopeptideophosphoglycan, was that from the epimastigote form of Trypanosoma cruzi. In the parasite these GIPLs form a dense glycocalyx (approximately $10^{7}$ GIPLs /cell) over the entire surface of the trypanosome [33]. This was the first study to provide a precise quantitative analysis of GIPLs and mucins on the surface of both epimastigotes and trypomastigotes. Highly purified GIPLs from the T. cruzi Y strain were analyzed by nuclear magnetic resonance spectroscopy (NMR), mass spectrometry and chemical degradation [26, 27].

Variations in glycan structure and lipid composition were detected in $T$. cruzi GIPLs purified from different strains. The main GIPL species from the $T$. cruzi Y strain has the structure Galf $\beta 1 \rightarrow 3 \mathrm{Man} \alpha 1 \rightarrow 2(\mathrm{Gal} f \beta 1 \rightarrow 3) \operatorname{Man} \alpha 1 \rightarrow 2 \mathrm{Man} \alpha 1$ $\rightarrow 6$ Man $\alpha 1-4\left(2\right.$-AEP-6)GlcN $\alpha 1 \rightarrow 6$ myo-inositol-1- $\mathrm{HPO}_{4^{-}}$ lignoceroylsphinganine [34]. However, GIPLs are mostly mixtures of beta-galactofuranose ( $\beta$-Galf)-, ethanolamine phosphate (EtNP)- and 2-aminoethylphosphonate (AEP)containing series 1 GIPLs $(\sim$ structure Gal $\beta \beta 1 \rightarrow 3$ Man $\alpha 1 \rightarrow 2$ $(\sim$ AEP/EtNP-6)Man $\alpha 1 \rightarrow 2$ Man $\alpha 1 \rightarrow \quad 6$ Man $\alpha 1 \rightarrow 4$ (AEP-6) GlcN $\alpha 1 \rightarrow 6$ - $m y$ o-inositol- $P$-ceramide) and series 2 GIPLs $(\sim$ structure $\quad$ Gal $f \beta 1 \rightarrow 3$ Man $\alpha 1 \rightarrow 2(\sim \mathrm{Gal} f \beta 1 \rightarrow 3)$ Man $\alpha 1 \rightarrow$ 2Man $\alpha 1-6$ Man $\alpha 1 \rightarrow 4$ (AEP-6)GlcN $\alpha 1 \rightarrow 6-$ myo $\quad$-inositol-Pceramide and Galf $\beta 1 \rightarrow 3$ Man $\alpha 1 \rightarrow 2$ Man $\alpha 1-6$ Man $\alpha 1 \rightarrow 4$ (AEP- 6)GlcN $\alpha 1 \rightarrow$ 6-myo-inositol-P-ceramide) [26, 27, 35, 36].

T. cruzi GIPLs are bioactive molecules and several biological effects have been described. First, GIPLs induce blockade of $\mathrm{CD}^{+}$and $\mathrm{CD} 8^{+} \mathrm{T}$-cell activation in vitro by antiCD3, superantigen or T. cruzi antigen. Furthermore, cell cycle blockade in $\mathrm{T}$ cells as well as reduced IL-2 secretion were observed. The suppressive effects of GIPLs on T cells are due to their ceramide moiety $[34,37]$. Second, on the contrary, GIPLs were demonstrated to have a co-stimulatory effect on mouse T-cell hybridomas, enhancing IL-2 production induced by suboptimal doses of mitogenic stimuli [38]. Third, the purified GIPL ceramide moiety induced $\mathrm{Ca}^{2+}$ mobilization, [34, 38]. Fourth, GIPLs are involved in parasite attachment to the midgut of the insect vector. The administration of $0.5 \mu \mathrm{M}$ of GIPLs inhibits up to $90 \%$ parasite infection in Rhodnius prolixus [39].

\subsection{Leishmania spp.}

In Leishmania , procyclic promastigotes, unlike amastigotes, express abundant quantities of a complex (protein-free) lipophosphoglycan (LPG) on their surface [22, 24] and the GPI anchored-metalloprotease (gp63) [40, 41]. Both glycoconjugates are thought to protect the promastigotes from hydrolytic enzymes in the sandfly gut, whereas LPG facilitates attachment to the insect gut epithelium. Transformation from non-infective dividing procyclics to infective nondividing metacyclics can involve changes to the LPG structure [31, 42-44]. In addition, Leishmania species contain GIPLs that form protective surface coats that have also been implicated in virulence and have been shown to mediate essential host-parasite interactions. GIPLs are necessary for the viability of both the insect and mammalian (amastigote) stages of the life cycle [45].

\section{2.a. $L P G$}

The LPG is the most abundant macromolecule on the surface of Leishmania promastigotes (approximately $6 \times 10^{6}$ copies per cell) during their development in the gut of the sandfly vector. Important roles have been described for the LPG coat including protection against the hydrolytic peptidase associated with bloodmeal digestion [46], binding of the parasite to the midgut wall [47], and, in some steps, it is required for the establishment of macrophage infections and for survival in the insect vector through complementation and oxidant resistance [24,25].

In all Leishmania species, the GPI anchor of LPG is composed of a 1-O-alkyl-2-lysophosphatidylinositol lipid anchor and a heptasaccharide core. A long phosphoglycan polymer composed of $15-30$ [Gal $\left.\beta 1,4 \mathrm{Man} \alpha 1-\mathrm{PO}_{4}\right]$ repeating units (substituted with other sugars in some species) is attached to the heptasaccharide core and is terminated by a capping oligosaccharide [25, 28, 42, 48]. The chains of the phosphoglycan are assembled in the Golgi apparatus and are modified with monosaccharide or glycan side chains and terminal capping oligosaccharides $[20,49,50]$. The attachment of the L. major promastigote to the midgut of $P$. papatasi is mediated by the terminally exposed galactose residues of the LPG, and the microvillar-associated proteins act as ligands for the parasite LPG [51-53]. Alterations to the length of the phosphoglycan chain, as well as changes in the nature of the side chains, occur during promastigote development in the sandfly midgut. In L. major the transition from procyclic to metacyclic promastigotes is also associated with the capping of galactose side chains with arabinose residues $[24,44]$. These changes result in an increase in the thickness of the surface coat and confer additional resistance to complement-mediated lysis, and they are also thought to be important in regulating the attachment of promastigotes to epithelial cells in the sandfly midgut $[24,43,54]$.

\section{2.b. GIPLs}

In the Leishmania genus, GIPLs are necessary for the viability of both the insect and mammalian (amastigote) stages of the life cycle $[32,45]$. Several types of structures have been found. For instance, in Leishmania donovani, type-1 GIPLs contain a $\alpha$ Man residue linked 1-6 to the Man residue of $\mathrm{Man} \alpha 1 \rightarrow 4 \mathrm{GlcN} \alpha 1 \rightarrow-6$ myo-inositol-1- $\mathrm{HPO}_{4}$-lipid [29 ]. This structure is present in Leishmania donovani [29]. 
The type-2 GIPLs are defined by the presence of a $\alpha \mathrm{Man}$ residue linked $1 \rightarrow 3$ to the Man residue of the common motif and have been described in L. major [30], L. mexicana [31], L. tropica and L.aethiopica [55] and L. adleri [56]. The hybrid-type GIPLs contain the branched structure Man $\alpha 1 \rightarrow$ 3 (Mana1 $\rightarrow$ 6) Man $\alpha \rightarrow 4 \mathrm{GlcNa} \rightarrow 6$ myo - inositol-1- $\mathrm{HPO}_{4}-$ lipid and are found in L. mexicana and L.donovani [25,28], L. tropica and L. aethiopica [55].

\subsection{Trypanosoma dionisii}

Trypanosoma (Schizotrypanum) dionisii is a bat trypanosomatid that is non-pathogenic for humans. It originates from the Europe and Latin America and is related to Trypanosoma cruzi. Recently, studies with mammalian cells showed that $T$. dionisii is highly infective in vitro, particularly when the infection process occurs without serum. In this case, the invasion is affected by agents known to interfere with the T. cruzi invasion process [57].

The GIPLs of $T$. dioinisii were purified by reversedphase and normal-phase liquid chromatography and analyzed by negative-ion mode electrospray-mass spectrometry (ESIMS). The phosphatidylinositol moieties were released by nitrous acid deamination and identified as ceramide- and alkylacylglycerol-containing species. The GIPLs were based on the same Man 1 1-2Man 1 1-2Man $\alpha 1-6 \mathrm{Man} \alpha 1-4\left(\mathrm{NH}_{2}-\right.$ $\left.\mathrm{CH}_{2} \mathrm{CH}_{2}-\mathrm{HPO}_{3}-\right)$ GlcN-PI core with single terminal Gal $f$ residue substitutions either on the terminal non-reducing Man or on the second $\alpha$ Man residue from the inositol and with either EtNP or AEP on the third $\alpha$ Man residue distant from the myo-inositol residue [58].

\subsection{Phytomonas spp.}

Phytomonas spp. are trypanosomatid parasites of plants. Their GIPLs were analyzed by chemical and enzymatic modifications, composition and methylation analyses, electrospray mass spectrometry and micro-sequencing after $\mathrm{HNO}_{2}$ deamination and $\mathrm{NaBH}_{4}$ reduction. The water-soluble head group of the second GIPL structure (see below) was also analyzed by ${ }^{1} \mathrm{H}$ NMR spectroscopy [29].

The GIPLs were analyzed in Phytomonas spp isolated from the rubber plant Euphorbia characias and they represent the first detailed characterization of surface molecules from this protozoa. Four GIPLs were detected with phosphatidylinositol moieties containing the fully saturated alkylacylglycerol lipids 1-O-hexadecyl-2-O-palmitoylglycerol and 1-O-hexadecyl- 2-01-O-hexadecyl-2- $O$-palmitoylglycerol and 1- $O$-hexadecyl--stearoylglycerol.These GIPLs are most similar to GIPL A of T.cruzi epimastigotes [35].

The structures of the GIPLs are: i) Man $\alpha 1 \rightarrow 2$ Man $\alpha 1 \rightarrow$ $6 \mathrm{Man} \alpha 1 \rightarrow 4 \mathrm{GlcNa} 1 \rightarrow-6 \mathrm{PI}$, ii) $\mathrm{Glc} \alpha 1 \rightarrow 2\left(\mathrm{NH}_{2}-\mathrm{CH}_{2} \mathrm{CH}_{2}-\right.$ $\mathrm{HPO}_{4}$ ) Man $\alpha 1 \rightarrow 2 \mathrm{Man} \alpha 1 \rightarrow 6 \mathrm{Man} \alpha \mathrm{c} 1 \rightarrow 4 \mathrm{GlcN} \alpha 1 \rightarrow-6 \mathrm{PI}$, iii) $\mathrm{Glc} \alpha 1 \rightarrow 2\left(\mathrm{NH}_{2} \mathrm{CH}_{2} \mathrm{CH}_{2}-\mathrm{HPO}^{4}\right.$-)Man $\alpha 1 \rightarrow 2 \mathrm{Man} \alpha 1 \rightarrow 6$ $\mathrm{Man} \alpha 1 \rightarrow-4\left(\mathrm{NH}_{2}-\mathrm{CH}_{2} \mathrm{CH}_{2}-\mathrm{HPO}_{4}-\mathrm{GlcN} 1 \rightarrow 6 \mathrm{PI}\right.$ and iv) $\mathrm{Glc} \alpha 1 \rightarrow 2 \mathrm{Glc} \alpha 1 \rightarrow 2\left(\mathrm{NH}_{2} \mathrm{CH}_{2}-\mathrm{CH}_{2}-\mathrm{HPO}_{4}-\right) \mathrm{Man} \alpha 1 \rightarrow 2 \mathrm{Man} \alpha 1$ $\rightarrow 6 \mathrm{Man} \alpha 1-4\left(\mathrm{NH}_{2} \mathrm{CH}_{2} \mathrm{CH}_{2}-\mathrm{HPO}_{4}\right)^{-}-\mathrm{GlcN} \alpha 1 \rightarrow 6 \mathrm{PI} . \quad[29$, 32].The presence of one and two $\alpha$ Glc residues are novel structural features for GIPLs. Unlike some Leishmania and Endotrypanum GIPLs [22] , Phytomonas GIPLs do not contain $\mathrm{Gal}$ residues.This finding may be significant since Phytomonas spp lives in the latex of Euphorbia characias, which contains a bivalent Gal-specific lectin, that might agglutinate the parasite [59].

The functions of these cell-surface GIPLs in trypanosomatid parasites remains obscure. However their abundance suggests that they may provide a protective role due to a dense negatively charged glycocalyx close to the surface of the plasma membrane, through which other macromolecules project [22].

\section{GLYCOSYLPHOSPHATIDYLINOSITOL (GPI)- ANCHORED PROTEINS}

The glycosylphosphatidylinositol (GPI) anchor is a glycolipid structure that is added post-translationally to the Cterminus of many eukaryotic proteins. This modification anchors the attached protein in the outer leaflet of the cell membrane [32, 60-62]. The GPI anchor is a complex structure comprising a phosphoethanolamine linker, a glycan core and a phospholipid tail (Fig. 5).

Proteins containing a GPI anchor are functionally diverse and play important roles in endocytosis, signal transduction, prion disease pathogenesis, complement regulation, antigenic presentation and the pathobiology of trypanosomal parasites [63-65]. In pathogenic protozoan parasites, the Tritryp group (e.g., Trypanosoma cruzi, Trypanosoma brucei, Leishmania major) molecules containing a GPI anchor may extensively coat the plasma membrane and are involved in host-parasite interaction processes, such as modulation and evasion of host immune responses.

\subsection{Trypanosoma cruzi}

T. cruzi GPI-anchored proteins are found in all evolutive forms and are encoded by thousands of members of multigene families, such as trans-sialidase (TS)/gp85 glycoprotein, mucin, mucin-associated surface proteins (MASP) and metalloproteinase gp63 [13]. Some of them, such as the TS/gp85 and mucins, have been shown to be very important for the infectivity of the parasite and for escaping the host immune response [8, 66-70]. Furthermore, GPI anchors from T. cruzi are pro-inflammatory molecules and are critical in modulation of the host immune response against the parasite $[9,71]$. Taking into consideration these important functions, GPI- anchored proteins and GPI anchors themselves seem to be possible targets for new therapies against Chagas disease.

\section{1.a. Mucins (TcMUC)}

Mucins are hydrophilic glycoproteins that bear a dense array of $O$-linked oligosaccharides with side chains containing Gal and GlcNAc (about $60 \%$ carbohydrate by weight) and are anchored to the plasma membrane via a glycosylphosphatidylinositol (GPI) moiety. Metacyclic and cellderived trypomastigote mucin-like molecules are sialylated by a parasite membrane-located trans-sialidase (TS) [72].

They were first described by Alves and Colli [73] as glycoproteins A, B, and C in non-infective epimastigotes. The core polypeptides of these glycoproteins are only 50-200 amino acids in length and their sequences are rich in Ser and Thr residues [67, 74-78]. The surface of Trypanosoma cruzi at different stages is covered by mucins. Acting at the interface between the parasite and both the vector and the infected host, these molecules provide protection against the 


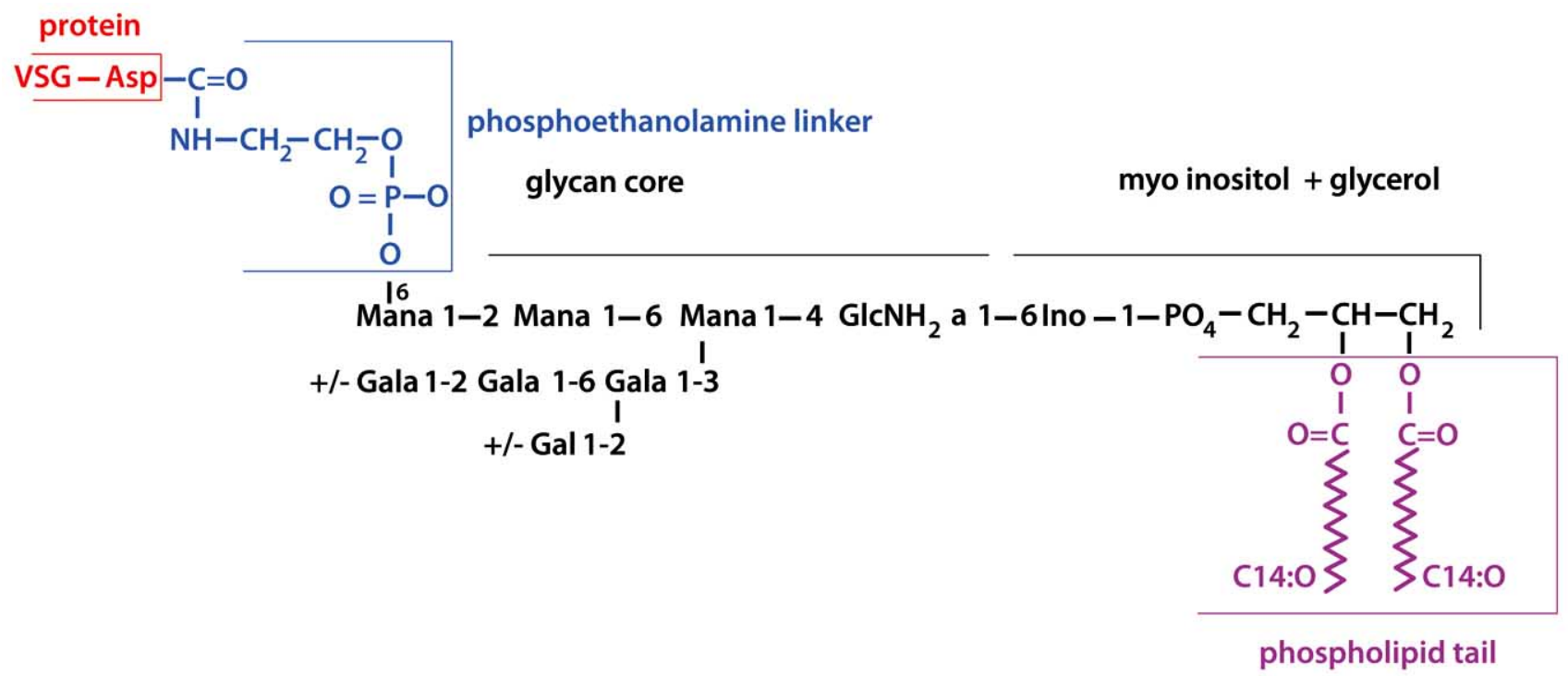

Fig. (5). Structure of the GPI anchor of Trypanosoma brucei bloodstream forms VSG. Based on Ferguson and collaborators [29].

vector and/or vertebrate-host-derived defense mechanisms and ensure the targeting and invasion of specific cells or tissues $[8,78]$.

T. cruzi mucins contain a complex family of mucin-like genes termed TcMUC. The groups of repetitive and nonrepetitive genes were designated TcMUC I and TcMUC II, respectively. The majority of the mucin molecules present on the surface of the cell-derived trypomastigotes belong to the TcMUC II group [8]. In fact, amastigote mucins are probably from the TcMUC I family/group. A second mucin gene family was identified that, despite having similar flanking regions to those of the TcMUC gene products, encodes proteins with their own diverse and remarkably short central regions [79, 80]. This gene family was therefore termed TcSMUG, for $T$. cruzi small mucin-like gene family. TcSMUG comprises 70-80 genes that were originally divided in two groups ( $\mathrm{S}$ for Small and $\mathrm{L}$ for Large) according to the size of their encoded mRNAs. Recently, the group $S$ gene products have been identified as the major $35-50 \mathrm{kDa}$ mucins expressed during the epimastigote stage [13].

Mucins can initially be divided into two major types: those present in the insect stages and those present in the mammalian stages. Mucins from both major insect-derived stages (epimastigotes and metacyclic trypomastigotes) run on SDS-PAGE as double or triple bands in the range of 35$50 \mathrm{kDa}$ and have almost identical amino acid and carbohydrate compositions. The only structural difference is that, in the mucins isolated from epimastigotes, an alkylacylglycerol residue is found in the GPI anchor whereas in the metacyclic trypomastigote, it is replaced by a ceramide [8]. In the epimastigote and metacyclic mucins, the GPI glycan core is mainly composed of the linear structure Man $1 \rightarrow 2$ Man $1 \rightarrow$ $2 \mathrm{Man} 1 \rightarrow 6 \mathrm{Man} 1 \rightarrow 4 \mathrm{GlcN}[67,81]$. In the metacyclic trypomastigote forms, mucins may facilitate parasite development and growth in the insect vector by allowing trypomastigotes to survive the activities of digestive enzymes. In metacyclic trypomastigotes, which successfully initiate infection of the mammalian gastrointestinal tract, the peptidase-resistant mucin may confer the ability to survive at extremely low $\mathrm{pH}$ and protection from proteolytic enzymes present in gastric secretions [82].

Mucins from cell-derived trypomastigotes (tGPI-mucins) appeared on SDS-PAGE as a smear spanning a wide range of molecular masses (60-200 kDa). They shared the sialic acid-containing epitope Ssp-3, which is crucial for mammalian-cell attachment and invasion and which might be involved in diverting the complement cascade [74]. Mass spectrometric analysis of tGPI-mucins showed the presence of their GPI, oligosaccharide and peptide regions [83, 84]. The oligosaccharides were $O$-glycosidically linked mainly to $\mathrm{Thr}$ residues in the peptide backbone via $\mathrm{N}$-acetylglucosaminyl units [77]. The attached lipid region is an alkylacylglycerol containing mainly unsaturated fatty acids at the $s n-2$ position of the glycerol moiety. The $O$-linked oligosaccharides are highly immunogenic to humans, resulting in the production of high-levels of trypanolytic anti-Gal antibodies [77]. In cell-derived trypomastigotes GPI glycan cores can be larger, containing a branch of Gal residues up to eight units in length [84], substituting a linear structure of Man1 $\rightarrow$ 2 Man $1 \rightarrow 2$ Man $1 \rightarrow 6$ Man $1 \rightarrow 4$ GlcN [81]. The established and putative functions of the mucin components are as follows: i) variable region - immune evasion and adhesion; ii) core region - the main $O$-glycosylation scaffold and immunogenicity; iii) glycans - protection, adhesion and immunogenicity; iv) glycosylphosphatidylinositol (GPI) anchor - anchorage and immunomodulation (Fig. 6; Table 3).

The trypomastigote (strain Y obtained from $\mathrm{LLCMK}_{2}$ cell culture) GPI structure was found to contain additional galactose residues and unsaturated acids in the $s n-2$ position of the alkylacyl-glycerolipid component. This feature is essential for the extreme efficiency of the trypomastigote GPI anchor in the induction of macrophage proinflammatory cytokines [84]. The TcMUC may also play an important protective role in the vertebrate forms and, in this case, an effective sialylation of the parasite seems to be critical. When the mucins are 

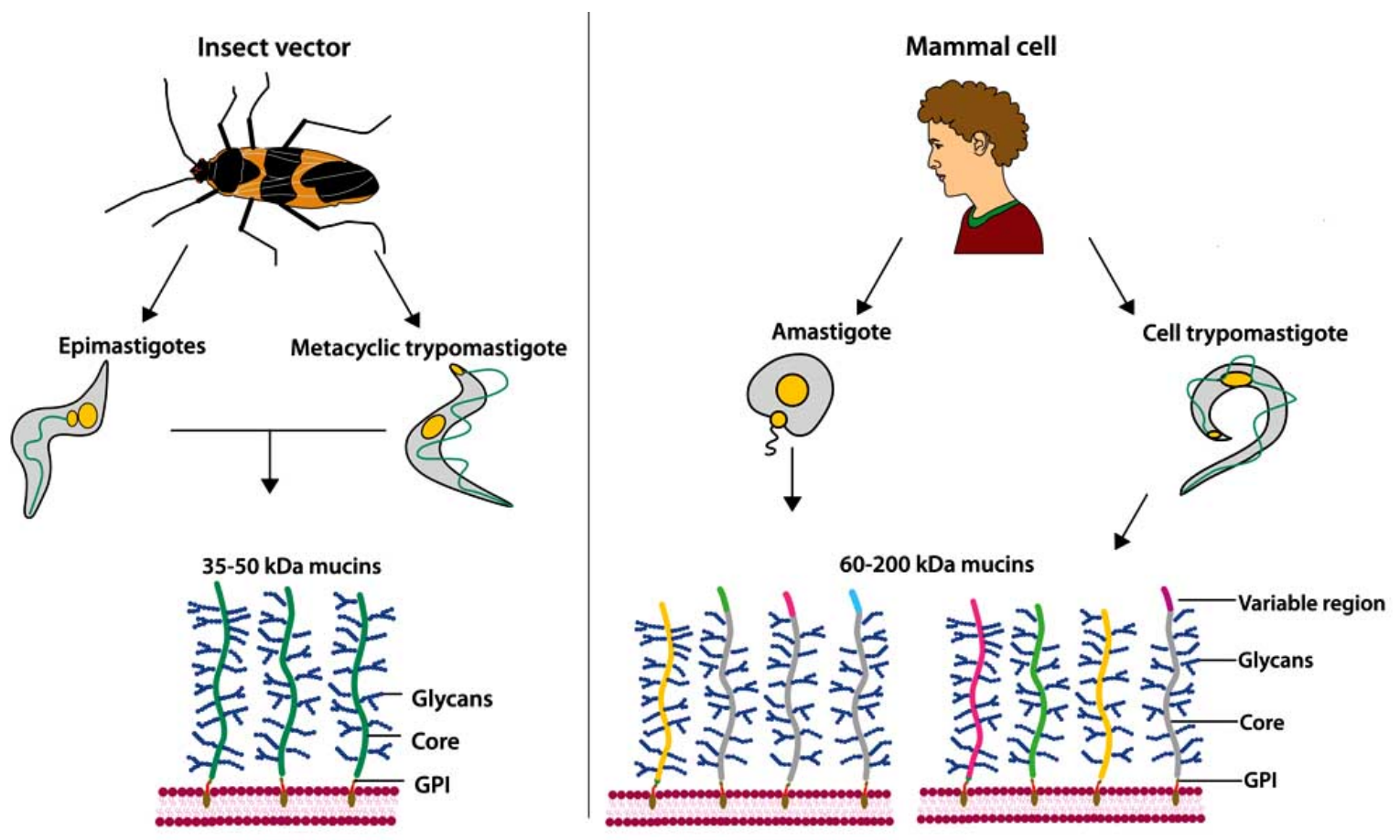

Fig. (6). Mucins in major Trypanosoma cruzi developmental forms in the insect vector and host cell (based on [8]).

Table 3. Some Functions of Trypanosoma cruzi Mucins

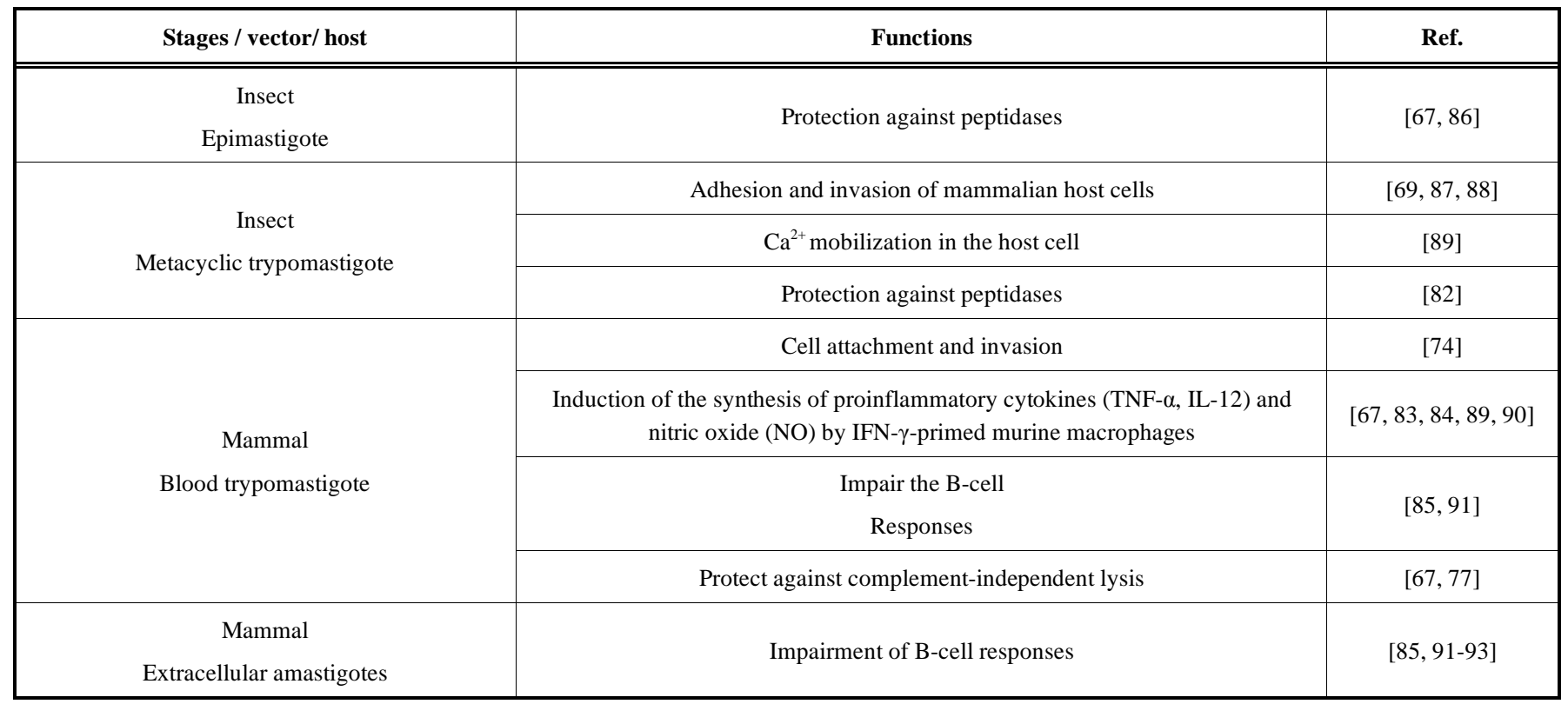

sialylated, each parasite acquires about $1 \times 10^{7}$ sialic acid residues, resulting in a strong negative charge on the surface. This negatively charged coat is thought to provide protection against complement-independent lysis induced by human anti-galactosyl antibodies $[67,68]$. The heterogeneity of the mucin core polypeptides expressed in mammal -dwelling stages of T.cruzi could have an additional protective effect against the host immune system. Antigenic cross-reactivity displayed by HV (hypervariable )-peptides might be one of the mechanism leading to the poor response directly towards them. A possible explanation could be the co-expression of multiple antigenically-related TcMUC I variants on the parasite surface impairing or delaying the maturation and/or leading to anergy of cross reactive B anf T lymphocytes [85].

\section{1.b. Trans-Sialidase (TS)}

Trans-sialidase (TS) is a glycoprotein that transfers sialic acid residues from host sialoglycoconjugates to parasite mucins but cannot use the CMP-sialic acid as a donor. TS activity has been postulated to enable $T$. cruzi to circumvent 
its lack of de novo synthesis of sialic acid and is crucial for the viability and propagation of the parasite [72, 74, 94-96, $33,101]$. These molecules are present on the $T$. cruzi surface coat albeit in much lower numbers than mucins. Together with mucins they are essential for the infectivity of the parasite and its escape from the host-immune response [9, 71, 97100]. Endotrypanum spp. (parasites of rain forest tree sloths) can also incorporate host-derived sialic acid into molecules of their own surface membrane [102].

The $t s$ gene family comprises at least 1,400 members [103], which can be classified into three groups. [66] Two of these groups (TS and TS I) are expressed by trypomastigotes (non-replicative metacyclic forms in insect vectors and mammalian invasive bloodstream forms). Both of them are anchored by glycosylphosphatidylinositol (GPI) to the surface membrane. They have two main regions: an $\mathrm{N}$-terminal catalytic region and a $\mathrm{C}$-terminal extension with tandem repeats of 12 amino acids (SAPA repeats). Trypomastigotes derived from infected mammalian cells express and release 20 times more TS activity than axenic metacyclic trypomastigotes, which correspond to the infective forms derived from the insect vector [98]. After cleavage of its glycosylphosphatidylinositol (GPI) anchor by the action of a phosphatidylinositol-phospholipase C (PI-PLC), TSs are shed into the bloodstream to up-regulate the early infection in phagocytic and non-phagocytic cells and to exert other biological effects on several cell types [66, 104].

The lipid moiety of the glycoinositolphospholipid that anchors the trans-sialidase to the membrane was characterized and two different kinds of lipids are linked through a phosphate bridge to a glycoinositol structure: hexadecylglycerol (Lyso-1-O-hexadecylglycerol) and ceramide (Npalmitoyl-sphinganine) in a 1:3 ratio [105].

\section{1.c. NETNES}

MacRae et al. [106] described the occurrence of NETNES, a complex glycoprotein with only 13 amino acids with the sequence AQENETNESGSID, in T. cruzi. The glycoprotein (NETNES) is a 13-amino acid peptide with up to five post-translational modifications, including one or two $\mathrm{N}$ linked glycans, two phosphate-linked mannose chains and a GPI anchor. The N-glycans are predominantly Man $\alpha 1 \rightarrow$ $6($ Man $\alpha 1 \rightarrow 3) \quad$ Man $\alpha 1 \rightarrow 6($ Man $\alpha 1 \rightarrow 3)$ Man $\alpha 1 \rightarrow 4$ GlcNAc $\alpha 1$ $\rightarrow 4$ GlcNAc $\alpha 1$-Asn; the phosphate-linked glycans are a mixture of (Man $\alpha 1$ - 2)O-3Man1-P-Ser; and the GPI anchor has the structure Mano1-(ethanolamine phosphate)Man $\alpha 1$ 2 Man $\alpha 1 \rightarrow$ 6Man $\alpha 1-4$ (2-aminoethylphosphonate-6)GlcN $\alpha 1$ $\rightarrow$ 6-myo-inositol-1-P-3(sn-1-O-(C16:0) alkyl-2-O-(C16:0) acylglycerol). Four putative NETNES genes were found in the T. cruzi genome data base [106].

\subsection{GPI-Anchored Proteins in Other Trypanosomatids}

In trypanosomatids, other well characterized GPIanchored molecules include the metallopeptidases, GP63 in Leshmania spp and VSG (variant surface glycoprotein) in Trypanosome brucei. Gp63 homologues have been found in all other trypanosomatids studied to date including heteroxenous members of Trypanosoma cruzi [107], T. brucei, [108111], phytoparasitic Phytomonas spp. and numerous monoxenous species $[112,113]$. They very likely perform roles different from those in Leishmania spp. [114].

\subsubsection{Trypanosoma brucei VSG}

The African trypanosome Trypanosoma brucei is covered with a dense layer of variant surface glycoproteins (VSG), which protect it from lysis by host complement via the alternative pathway in the mammalian bloodstream [6, 109]. The parasite evades the immune system by periodically replacing the existing VSG coat with a different one. This phenomenon is known as antigenic variation, and it allows the trypanosome to maintain a chronic infection [115]. When bloodstream-form parasites are ingested by the tsetse fly, they differentiate into the procyclic form in the insect midgut and colonize it. Replacement of VSG with procyclin is a hallmark of the transformation of bloodstream stage trypanosomes into the procyclic form. The procyclic trypanosomes express a different cell surface coat that includes about $3 \mathrm{x}$ $10^{6}$ procyclin glycoproteins and about $1 \times 10^{6}$ poly-Nacetyllactosamine containing free GPIs [116-119]. Procyclins are glycosylphosphatidylinositol (GPI)-anchored proteins with either five or six pentapeptide repeats (GPEET procyclin) or up to 30 glutamic acid-proline dipeptide repeats (EP procyclin) that confer a rod-like structure to the protein [120-122]. Procyclin anchors are complex and are characterized by the presence of large poly disperse branched $\mathrm{N}$-acetyllactosamine (Gal $\beta 1-4 \mathrm{GlcNAc})$ - and lactoN-biose (Gal $\beta 1-3 G l c N A c)$-containing side-chains that can be capped with $\alpha 2-3$-linked sialic acid residues [100 ]. The branched side-chains of the anchor form a dense glycocalyx that contributes to the protective function of the coat against digestive enzymes in the fly midgut [123]. The lipid moiety of gp63 is composed of alkylacylglycerol [22, 124].

GPEET and EP procyclins contain similar GPI membrane anchors. These are based on the ubiquitous ethanolamine-P-6Man $\alpha 1-2$ Man $\alpha 1-6$ Man $\alpha 1-4 \mathrm{GlcN} \alpha 1-6 \mathrm{PI}$ core: the $\mathrm{PI}$ lipid has a 2-O-acyl-myo-inositol-1-P-sn-2-1yso-1-Oacylglycerol structure [120-122].

\subsubsection{Leishmania spp. gp63}

Leishmania parasites are coated by a characteristic glycocalyx of molecular components that play a critical role in the initial contact between the parasite and its host environment. The gp63 from Leishmania spp, also referred to as a promastigote surface peptidase (PSP), leishmanolysin and major surface peptidase (MSP), is a metallopeptidase related protein associated with virulence and pathogenicity in this trypanosomatid $[7,125,126]$.The enzyme corresponds to the most abundant surface glycoprotein in promastigotes and is anchored via a glycosylphosphatidylinositol (GPI) anchor [127]. Gp63 plays a crucial role in complement fixation and processing, which protect Leishmania in mammalian hosts $[126,128]$. Other studies have demonstrated that gp63 defends the parasite against antimicrobial peptides such as defensins and pexiganans [129]. The high catalytic activity of gp63 at mammalian body temperature favors the dissemination of the parasite as it digests constituents of the extracellular matrix of the host such as collagen type IV, fibronectin and laminin $[130,131]$.

Several species of Leishmania spp. release proteolytically active gp63 into the extracellular medium presumably facilitating the propagation of the parasite $[131,132]$. 
In addition, fragments from gp63-processed fibronectin can protect parasites within macrophages, because they attenuate production of reactive oxygen intermediates and favor amastigote proliferation [133]. gp63 has also been suggested to maximize promastigote binding, to participate in internalization in macrophages and to promote complementdependent adhesion [134]. Moreover coating polystyrene surfaces with gp63 enhances the in vitro spreading of fibroblasts [135].

The expression of specific gp63 genes in the intracellular amastigote form implies an intra-host cell function for this peptidase. Curiously, the identification of the myristoylated alanine-rich $\mathrm{C}$ kinase substrate related protein (MRP), a cytosolic protein associated with the actin network of macrophages, as a substrate of gp63 reinforces the potential of this enzyme to modulate host cell activities within the intracellular space [134].

Gp63 has been recently reported to cleave multiple intracellular proteins and to participate actively in p38 mitogenactivated protein kinase inactivation. A rearrangement of the actin cytoskeleton and marked modification of the profile of protein tyrosine phosphorylation in fibroblasts infected with Leishmania major has been described. Correspondingly, exposure to L. major resulted in degradation of the phosphorylated adaptor protein $\mathrm{p} 130 \mathrm{Cas}$ and the protein-tyrosine phosphatase-PEST [134, 136, 137].

In addition, a recent study by Gomes and collaborators [138] reported that gp63 is the key Leishmania-virulence factor that modulates macrophage protein tyrosine phosphatases (PTPs) and revealed an essential role for PTP1B in the progression of cutaneous leishmaniasis in infected mice. The mechanism underlying protein tyrosine phosphatase (PTP) modulation involves the proteolytic activity of the Leishmania surface protease gp63. Furthermore, the authors reported a mechanism whereby Leishmania gp63 accesses the macrophage intracellular medium in part by a lipid raft-dependent mechanism, allowing a direct interaction with host protein substrates. The internalization of gp63, a key Leishmania virulence factor, into host macrophages is a strategy that the parasite uses to interact and survive within its host [138].

\section{PERSPECTIVES}

A huge number of glycosphingolipid structures (GSLs) have been identified in mammalian cells. These cell-surface molecules participate in cell physiology and play important roles in cell recognition and in the modulation of function of receptors, etc. In trypanosomatids, glycolipid analysis is undergoing rapid expansion. Glycosphingolipids (GSLs) have been characterized in $T$. cruzi, Leishmania spp. and some non-pathogenic trypanosomatids. Cell surface glycolipids/glycoproteins that form essential surface coats for survival of parasites in their various hosts were also identified. Many of these glycoconjugates are attached via glycosylphosphatidylinositol (GPI) anchors. However, the function of some of these molecules has remained largely unknown. A combination of isolation and separation technologies, as well as the use of mass spectrometry, for glycolipid structural characterization is required to unravel functional aspects of these cell surface molecules and to gain a better understanding of their role in infectious diseases. Considerable advances have recently been made in fields such as liquidchromatography- Mass spectrometry (LC-MS) of glycolipids from mammalian cells [139], GPI-anchored proteomics of Plamodium falciparum [140], GPIomics of T.cruzi [13] and glycolipid arrays to study antitoxic malaria response [141]. The combination of these sensitive and powerful techniques has allowed us to increase our structural and functional knowkedge of a wide variety of glycoconjugates an other macromolecules expressed by different protozoa.

\section{ACKNOWLEDGEMENTS}

We thank David Graham Straker for helpful comments on previous versions of the manuscript. Research was carried out in the authors' laboratories, included the authors of this review, and was supported by grants and fellowships from FAPERJ, MCT-CNPq and CAPES. Address for reprint requests and other correspondence: Eliana Barreto-Bergter, Instituto de Microbiologia Prof. Paulo de Góes, UFRJ, Centro de Ciências da Saude, bloco I, Cidade Universitaria, 21949-900, Rio de Janeiro, RJ, Brazil E-mail: eliana.bergter@micro.ufrj.br

\section{REFERENCES}

[1] Suzuki E, Tanaka AK, Toledo MS, Levery SB, Straus A, Takahashi HK. Trypanosomatid and fungal glycolipids and sphingolipids as infectivity factors and potential targets for development of new therapeutic strategies. Biochim Biophys Acta 2008; 1780: 362-9.

[2] Vermelho AB, Hogge L, Barreto-Bergter E. Isolation and characterization of a neutral glycosphingolipid from the epimastigote forms of Trypanosoma mega. J Protozool 1986;33: 208-13.

[3] Barreto-Bergter E, Vermelho AB, Hartmann R, Pohlentz G, Klein RA, Egge H. Structural characterization of neutral glycosphingolipid from Trypanosoma cruzi. Mol Biochem Parasitol 1992; 1: 263-70.

[4] Villas Boas MHS, Silva RB, Wait R, Rodrigues ML,BarretoBergter E. Ceramide glycosylation and fatty acid hydroxylation influence serological reactivity of Trypanosoma cruzi glycosphingolipids. FEMS Microbiol Lett 2005; 244: 47-52.

[5] Denny PW, Field MC, Smith DF. GPI-anchored proteins and glycoconjugates segregate into lipid rafts in Kinetoplastida. FEBS Lett 2001; 49: 148-53.

[6] Pays E, Vanhamme L, Perez-Morga D. Antigenic variation in Trypanosoma brucei: facts, challenges and mysteries. Curr Opin $\mathrm{Mi}$ crobiol 2004; 7 :369-74.

[6] Pays E, Vanhamme L, Perez-Morga D. Antigenic variation in Trypanosoma brucei: facts, challenges and mysteries. Curr Opin $\mathrm{Mi}$ crobiol 2004; 7 :369-74.

[7] Yao C, Donelson JE, Wilson ME. The major surface protease (MSP or GP63) of Leishmania sp. Biosynthesis, regulation of expression, and function. Mol Biochem Parasitol 2003; 132: 1-16.

[8] Buscaglia CA, Campo VA, Frasch AC, Di Noia JM. Trypanosoma cruzi surface mucins: host-dependent coat diversity. Nat Rev Microbial 2006; 4(3):229-36

[9] Almeida IC , Gazzinelli RT. Proinflammatory activity of glycosylphosphatidylinositol anchors derived from Trypanosoma cruzi: structural and functional analyses. J Leukoc Biol 2001; 70: 467-77.

[10] Hakomori S. Structure and function of sphingoglycolipids in transmembrane signaling and cell-cell interactions. Biochem SocTrans 1993; 21:583-95.

[11] Kasahara K, Sanai Y. Functional roles of glycosphingolipids in signal transduction via lipid rafts. Glycoconjugate J 2000; 17:15362

[12] Barreto-Bergter E, Pinto MR, Rodrigues ML. Structure and biological functions of fungal cerebrosides. An Acad Bras Cienc 2004; 76(1): 67-84

[13] Nakayasu ES, Yashunsky DV, Nohara LL, Torrecilhas AC, Nikolaev AV, Almeida IC. GPIomics: global analysis of glyco- 
sylphosphatidylinositol-anchored molecules of Trypanosoma cruzi. Mol Syst Biol 2009; 5: 261.

[14] Kirchhoff L, Weiss LM, Wittner M, Tanowitz HB, Parasitic diseases of the heart. Front Biosci 2004; 9:706-23.

[15] Georgopapadakou NH . Antifungals targeted to sphingolipid synthesis: focus on inositol phosphorylceramide synthase. Expert Opin Investig Drugs 2000; 9: 1787-96.

[16] Villas Boas MHS, Bahia MCF, Oliveira TC, Travassos LR, Barreto-Bergter E. Reactivity of chagasic sera with crude and highly purified glycosphingolipid fractions from Trypanosoma cruzi. J Clin Lab Anal 1994; 8:260-6.

[17] Cossy-Isasi S, Condat CA, Sibona GJ. Why does GM1 induce a potent beneficial response to experimental Chagas disease? Why does GM1 induce a potent beneficial response to experimental Chagas disease? HFSP J 2009; 3(2): 142-51.

[18] Cossy-Isasi S, Fernández A, Paglini P, Bronia D. GM1 ganglioside induced myocardial restoration and survival of mice with experimental Chagas' disease. Acta Trop 1999; 73: 295-302.

[19] Cossy-Isasi SM, Rodríguez M, Pereira BMI, Díaz-luján C, Fretes, RE, Haüen DI. Trypanosoma cruzi: Altered parasites after in vitro treatment with gangliosides, a therapeutic agent in experimental Chagas' disease. Exp Parasitol 2009; 122: 218-25.

[20] Straus AH, Levery SB, Jasiulionis MG, et al. Stage-specific glycosphingolipids from amastigote forms of Leishmania (L) amazonensis. Immunogenicity and role in parasite binding and invasion of macrophages. J Biol Chem 1993; 268: 13723-30.

[21] Tanaka AK, Gorin PAJ, Takahashi HK, Straus AH. Role of Leishmania (Leishmania) amazonensis amastigote glycosphingolipids in macrophage infectivity. Braz J Med Biol Res 2007; 40: 799-806.

[22] McConville MJ, Ferguson MAJ. The structure, biosynthesis and function of glycosyl-phosphatidylinositols in the parasitic protozoa and higher-eukaryotes. Biochem J 1993; 294:305-24.

[23] Routier FH, Da Silveira EX, Wait R, Jones C, Previato JO, Mendonça-Previato L. Chemical characterisation of glycosylinositolphospholipids of Herpetomonas samuelpessoai. Mol Biochem Parasitol 1995; 69: 81-92

[24] Ilgoutz SC, McConville MJ. Function and assembly of the Leishmania surface coat. Int J Parasitol 2001; 31(9): 899-908.

[25] Späth GF, Garraway AL, Turco SJ, Beverley S. The role(s) of lipophosphoglycan (LPG) in the establishment of Leishmania major infections in mammalian hosts. PNAS 2003; 100: 9536-41.

[26] Previato JO, Gorin PAJ, Mazurek M, et al. Primary structure of the oligosaccharide chain of lipopeptidophosphoglycan from Trypanosoma cruzi epimastigotes. J Biol Chem 1990; 265: 2518-26.

[27] Lederkremer RM, Lima C, Ramirez MI, Ferguson MAJ, Homans SW, Thomas-Oates JE. Complete structure of the glycan of lipopeptidophosphoglycan from Trypanosoma cruzi epimastigotes. J Biol Chem 1991; 266: 23670-5.

[28] McConville MJ, Blackwell JM. Developmental changes in the glycosylated phosphatidylinositols of Leishmania donovani. Characterization of the promastigote and amastigote glycolipids. J Biol Chem 1991; 266:15170- 9.

[29] Redman CA, Schneider P, Mehlert A, Ferguson MAJ. The glycoinositol-phospholipids of Phytomonas. Biochem J 1995; 311 : 495-503.

[30] McConville MJ, Homans SW, Thomas-Oates JE, Dell A, Bacic A. Structures of the glycoinositolphospholipids from Leishmania major: a family of novel galactofuranose-containing glycolipids. J Biol Chem 1990; 265: 7385-94

[31] McConville MJ, Collidge TAC, Ferguson MAJ, Schneider P. The Glycoinositolphospholipids of Leishmania mexicana promastigotes: evidence for the presence of three distinct pathways of biosynthesis. J Biol Chem 1993; 268: 15595-604.

[32] Ferguson MAJ. The surface glycoconjugates of trypanosomatid parasites. Phil Trans R Soc Lond 1997; 352: 1295-302.

[33] Pereira-Chioccola VL, Acosta-Serrano A, Correia de Almeida I, et al. Mucin-like molecules form a negatively charged coat that protects Trypanosoma cruzi trypomastigotes from killing by human anti- $\alpha$-galactosyl antibodies. J Cell Sci 2000; 113: 1299-307.

[34] Dos Reis GA, Peçanha LM, Bellio M, Previato JO, MendonçaPreviato L. Glycoinositol phospholipids from Trypanosoma cruzi transmit signals to the cells of the host immune system through both ceramide and glycan chains. Microbes Infect 2002 ; 9:100713.

[35] Lederkremer RM, Lima CE, Ramirez MI, Goncalves MF, Colli W. Hexodecyl/palmitoylglycerol or ceramide is linked to similar glycophosphoinositol onchor-like structures in Trypanosoma cruzi. Eur J Biochem 1993; 218; 929-36.

[36] MacRae J, Ferguson MAJ. A robust and selective method for the quantification of glycosylphosphatidylinositols in biological samples. Glycobiology 2005; 15: 131-8.

[37] Gomes NA, Previato JO, Zingales B, Mendonça-Previato L, DosReis GA. Down-regulation of T lymphocyte activation in vitro and in vivo induced by glycoinositolphospholipids from Trypanosoma cruzi. Assignment of the T cell-suppressive determinant to the ceramide domain. J Immunol 1996; 56: 628-63.

[38] Bellio M, Liveira AC, Mermelstein CS, et al .Costimulatory action of Glycoinositolphospholipids from Trypanosoma cruzi: increased interleukin 2 secretion and induction of nuclear translocation of the nuclear factor of activated T cells-1. FASEB J 1999; 13: 1627-163

[39] Nogueira NF, Gonzalez MS, Gomes JE, et al. Trypanosoma cruzi: involvement of glycoinositolphospholipids in the attachment to the luminal midgut surface of Rhodnius prolixus. Exp Parasitol 2007; 116(2): 120-8.

[40] Davies CE, CooperAM, Peacock C, Lane RP, Blackwell JM. Expression of LPG and GP63 by different development stages of Leishmania major in the sandfly, Phlebotomus papatasi. Parasitology 1990; 101: 337-43.

[41] Pimenta P, Saraiva EM, Sacks DL. The comparative fine structure and surface glycoconjugate expression of three life stages of Leishmania major. Exp Parasitol 1991; 72: 191-204.

[42] Turco SJ, Descoteaux A. The lipophosphoglycan of Leishmania parasites. Annu Rev Microbiol 1992; 46: 65-94.

[43] Sacks DL, Pimenta PF, McConville MJ, Schneider P, Turco, SJ Stage-specific binding of Leishmania donovani to the sandfly vector midgut is regulated by conformational changes in the abundant surface lipophosphoglycan. J Exp Med1995; 181: 685-97.

[44] Saraiva EMB, Pimenta PFP, Brodin TN, Rowton E, Modi,GB, Sacks DL. Change in lipophosphoglycan and gene expression associated with the development of Leishmania major in Phlebotomus papatasi. Parasitology 1995; 111: 275- 87.

[45] Ilgoutz SC, Zawadzki JL, Ralton JE, McConville MJ. Evidence that free GPI glycolipids are essential for growth of Leishmania mexicana. EMBO J 1999; 18: 2746-55.

[46] Borovsky D, Schlein Y. Trypsin and chymotrypsin-like enzymes of the sandfly Phlebotomus papatasi infected with Leishmania and their possible role in vector competence. Med Vet Entomol 1987; 1: 235-42.

[47] Sacks DL, Saraiva EM, Rowton E, Turco SJ, PimentaM PF. The role of the lipophosphoglycan of Leishmania in vector competence. Parasitology 1994; 108: 55-62.

[48] Descoteaux A, Turco SJ. Glycoconjugates in Leishmania infectivity. Biochim Biophys Acta 1999; 1455: 341- 52.

[49] Bates PA, Hermes I, Dwyer DM. Golgi-mediated post-translational processing of secretory acid phosphatase by Leishmania donovani promastigotes. Mol Biochem Parasitol 1990; 39, 247-55.

[50] Ha DS, Schwarz JK, Turco SJ, Beverley SM. Use of the green fluorescent protein as a marker in transfected Leishmania. Mol Biochem Parasitol 1996; 77: 576-4.

[51] Pimenta PF, Turco SJ, McConville MJ, Lawyer PG, Perkins PV. Sacks DL. Stage- specifc adhesion of Leishmania promastigotes to the sandfly midgut. Science 1992; 256:1812-5.

[52] Dillon RJ, Lane RP. Detection of Leishmania lipophosphoglycan binding proteins in the gut of the sandfly vector. Parasitology 1999 ; 118: 27-32.

[53] Kamhawi S, Modi GB, Pimenta PF, Rowton E, Sacks DL. The vectorial competence of Phlebotomus sergenti is specific for Leishmania tropica and is controlled by species-specific, lipophosphoglycan-mediated midgut attachment. Parasitology 2000; 121: 25-33.

[54] Butcher BA, Turco SJ, Hilty BA, Pimenta PF, Panunzio M, Sacks DL. Deficiency in $\beta 1,3$-galactosyltransferase of a Leishmania ma- 
jor lipophosphoglycan mutant adversely influences the Leishmania sandfly interaction. J Biol Chem 1996; 271: 20573-9.

[55] Schneider P, Schnur LF, Jaffe CL, Ferguson MAJ, McConville MJ. Glycoinositol-phospholipid profiles of fourserotypically distinct Old World Leishmania strains. Biochem J 1994; 304: 603-9.

[56] Previato JO, Jones C, Wait R, et al. Leishmania adleri, a lizard para site, express structurally similar glycoinositolphospholipids to mammalian Leishmania. Glycobiology 1997; 7: 687-95.

[57] Oliveira MP, Cortez M, Maeda FY, et al. Unique behavior of Trypanosoma dionisii interacting with cells: mammalian invasion, intracellular growth, and nuclear localization. Acta Trop 2009; 110(1): 65-74.

[58] Branquinha MH, Vermelho AB, Almeida IC, Mehlert A, Ferguson MA. Structural studies on the polar glycoinositol phospholipids of Trypanosoma (Schizotrypanum) dionisii from bats. Mol Biochem Parasitol 1999; 102(1): 179-89.

[59] Barbieri L, Falasca A, Franceschi C, Licastro F, Rossi Ca, Stirpe F. Purification and properties of two lectins from the latex of the euphorbiaceous plants Hura crepitans L. (sand-box tree) and Euphorbia characias L. (Mediterranean spurge). Biochem J 1983; 215(3): 433-9.

[60] Ferguson MA, Halder K, Cross, GA. Trypanosoma brucei variant surface glycoprotein has a sn-1,2-dimyristylglycerol membrane anchor at its COOH-terminus. J Biol Chem 1985; 260: 4963-8.

[61] Ferguson MA. The structure, biosynthesis and functions of glycosylphosphatidylinositol anchors, and the contributions of trypanosome research. J Cell Sci 1999; 112: 2799-809.

[62] Paulick MG, Bertozzi CR. The glycosylphosphatidylinositol anchor: a complex membrane-anchoring structure for proteins. Biochemistry 2008; 47(27): 6991-7000.

[63] Nosjean O, Briolay A, Roux B. Mammalian GPI proteins: sorting, membrane residence and functions. Biochim Biophy Acta 1997; $1331 ; 153-86$

[64] Chesebro B, Trifilo M, Race R, et al. Anchorless prion protein results in infectious amyloid disease without clinical scrapie. Science 2005; 308: 1435-9.

[65] Orlean P, Menon AK. Thematic review series: lipid posttranslational modifications. GPI anchoring of protein in yeast and mammalian cells, or: how we learned to stop worrying and love glycophospholipids. J Lipid Res 2007; 48: 993-1011.

[66] Frasch ACC. Functional diversity in the transialidase and mucin families in Trypanosoma cruzi. Parasitol Today 2000; 16(7): 282-6.

[67] Acosta-Serrano A, Almeida IC, Freitas-Junior LH, Yoshida N, Schenkman S. The mucin-like glycoprotein super-family of Trypanosoma cruzi: structure and biological roles. Mol Biochem Parasitol 2001; 114(2): 143-50.

[68] Almeida IC, Ferguson MA, Schenkman S, Travassos LR. GPIanchored glycoconjugates from Trypanosoma cruzi trypomastigotes are recognized by lytic anti $\alpha$-galactosyl antibodies isolated from patients with chronic Chagas' disease. Braz J Med Biol Res 1994; 27: 443-7.

[69] Yoshida N, Mortara RA, Araguth MF, Gonzalez JC, Russo M. Metacyclic neutralizing effect of monoclonal antibody 10D8 directed to the 35- and 50-kilodalton surface glycoconjugates of Trypanosoma cruzi. Infect Immun1989; 57: 1663-7.

[70] Alves MJ, Colli W. Role of the gp85/trans-sialidase superfamily of glycoproteins in the interaction of Trypanosoma cruzi with host structures. Subcell Biochem 2008; 47: 58-69.

[71] Gazzinelli RT, Denkers EY. Protozoan encounters with Toll-like receptor signalling pathways: implications for host parasitism. Nat Rev Immunol 2006; 12: 895-906.

[72] Schenkman S, Eichinger D, Pereira ME, Nussenzweig V. Structural and functional properties of Trypanosoma trans-sialidase. Annu Rev Microbiol 1994; 48: 499-523.

[73] Alves MJ, Colli W. Glycoproteins from Trypanosoma cruzi: partial purification by gel chromatography. FEBS Lett 1975; 52, 188-90.

[74] Schenkman S, Jiang MS, Hart GW, Nussenzweig V. A novel cell surface trans-sialidase of Trypanosoma cruzi generates a stagespecific epitope required for invasion of mammalian cells. Cell 1991; 65: 1117-25.

[75] Previato JO, Jones C, Gonçalves LPB, Wait R, Travassos, LR, Mendonça-Previato L. O-Glycosidically linked N-acetylgluco- samine-bound oligosaccharides from glycoproteins of Trypanosoma cruzi. Biochem J 1994; 300: 151-9.

[76] Previato JO, Sola-Penna M, Agrellos OA, et al. Biosynthesis of O$\mathrm{N}$-acetylglucosamine linked glycans in Trypanosoma cruzi. Characterization of the novel uridine diphospho-N-acetyl glucosamine:polypeptide $\mathrm{N}$-acetylglucosaminyl transferase-catalyzing formation of $\mathrm{N}$-acetylglucosamine alpha $1 \longrightarrow$ O-threonine. J Biol Chem 1998; 273: 14982-8.

[77] Almeida IC, Ferguson MAJ, Schenkman S, Travassos LR. Lytic anti- $\alpha$-galactosyl antibodies from patients with chronic Chagas disease recognize novel O-linked oligosaccharides on mucin-like glycosyl-phosphatidylinositol-anchored glycoproteins of Trypanosoma cruzi. Biochem J 1994; 304: 793-802.

[78] Hicks SJ, Theodoropoulos G, Carrington SD, Corfield AP, The role of mucins in Host-Parasite Interactions. Parasitol Today 2000; 16(11): 476-81.

[79] Buscaglia CA, Campo VA, Di Noia JM, et al. The surface coat of the mammal-dwelling infective trypomastigote stage of Trypanosoma cruzi is formed by highly diverse immunogenic mucins. J Biol Chem 2004; 279 (16): 15860-9.

[80] Di Noia J MD, Orso I, Sánchez DO, Frasch AC. AU-rich elements in the 3'-untranslated region of a new mucin-type gene family of Trypanosoma cruzi confers mRNA instability and modulates translation efficiency. J Biol Chem 2000; 275: 10218-27.

[81] Previato JO, Jones C, Xavier MT, et al. Structural characterization of the major glycosylphosphatidylinositol membrane-anchored glycoprotein from epimastigote forms of Trypanosoma cruzi Y-strain. J Biol Chem 1995; 270: 7241-50.

[82] Hoft DF, Farrar PL, Kratz-Owens K, Shaffer D. Gastric invasion by Trypanosoma cruzi and induction of protective mucosal immune responses. Infect Immun 1996; 64: 3800-10.

[83] Camargo MM, Almeida IC, Pereira MES, Ferguson MAJ, Travassos LR, Gazzinelli RT. GPI-anchored mucin-like glycoproteins isolated from Trypanosoma cruzi trypomastigotes initiate the synthesis of pro-inflammatory cytokines by macrophages. J Immunol 1997; 158: 5890-901.

[84] Almeida IC, Camargo MM, Procópio DO, et al. Highly purified glycosylphosphatidylinositols from Trypanosoma cruzi are potent proinflammatory agents. EMBO J 2000; 19: 1476-85.

[85] Campo VA, Buscaglia CA, Di Noia JM, Frasch M. Immunocharacterization of mucin-type proteins from the intracellular stage of Trypanosoma cruzi. Microbes Infect 2006; 8: 401-9.

[86] Mortara RA, da Silva S, Araguth MF, Blanco SA, Yoshida N. Polymorphism of the 35- and 50-kilodalton surface glycoconjugates of Trypanosoma cruzi metacyclic trypomastigotes. Infect Immun 1992; 60: 4673-8.

[87] Ruiz RC, Rigoni VL, Gonzalez J, Yoshida N. The 35/50 kDa surface antigen of Trypanosoma cruzi metacyclic trypomastigotes, an adhesion molecule involved in host cell invasion. Parasite Immunol 1993; 15: 121-5.

[88] Ruiz RC, Favoreto S, Dorta ML, et al. Infectivity of Trypanosoma cruzi strains is associated with differential expression of surface glycoproteins with differential $\mathrm{Ca}^{2+}$ signalling activity. Biochem $\mathrm{J}$ 1998; 330: 505-11.

[89] Dorta ML, Ferreira AT, Oshiro ME, Yoshida N. $\mathrm{Ca}^{2+}$ signal induced by Trypanosoma cruzi metacyclic trypomastigote surface molecules implicated in mammalian cell invasion. Mol Biochem Parasitol 1995; 73: 285-9.

[90] Gazzinelli RT, Camargo MM, Almeida IC, et al. Identification and characterization of protozoan products that trigger the synthesis of IL-12 by inflammatory macrophages. Chem Immunol 1997; 68: 136-52.

[91] Millar A, Wleklinski-Lee M, Kahn SJ. The surface protein superfamily of Trypanosoma cruzi stimulates a polarized Th1 response that becomes anergic. J Immunol 1999; 162: 6092-9.

[92] Pitcovsky TA, Buscaglia CA, Mucc IJ, Campetella O. A functional network of intramolecular cross-reacting epitopes delays the elicitation of neutralizing antibodies to Trypanosoma cruzi transialidase. J Infect Dis 2002; 186, 397-404.

[93] Cruz LJ, Iglesias E, Aguilar JC, Cabrales A, Reyes O, Andreu D. Different immune response of mice immunized with conjugates containing multiple copies of either consensus or mixotope ver- 
sions of the V3 loop peptide from human immunodeficiency virus type 1. Bioconjug Chem 2004; 15: 1110-7.

[94] Previato JO, Andrade AF, Pessolani MC, Mendonça-Previato L. Incorporation of sialic acid into Trypanosoma cruzi macromolecules. A proposal for a new metabolic route. Mol Biochem Parasitol 1985; 16: 85-96.

[95] Zingales B, Carniol C, Lederkremer R, Colli W. Direct sialic acid transfer from a protein donor to glycolipids of trypomastigote forms of Trypanosoma cruzi Mol Biochem Parasitol 1987; 26: 13544.

[96] Schenkman S, Eichinger D. Trypanosoma cruzi trans-sialidase and cell invasion. Parasitol Today 1993; 9: 218-22.

[97] Frasch ACC. Trans-sialidases in the insect-vector stages of African and American trypanosomes. Parasitol Today 1994; 10, 170-1.

[98] Rubin-de-Celis SS, Uemura H, Yoshida N, Schenkman S. Expression of trypomastigote trans-sialidase in metacyclic forms of Trypanosoma cruzi increases parasite escape from its parasitophorous vacuole. Cell Microbiol 2006; 12: 1888-98.

[99] Villalta F, Madison MN, Kleshchenko YY, Nde PN, Lima MF. Molecular analysis of early host cell infection by Trypanosoma cruzi. Front Biosci 2008; 13: 3714-34.

[100] Nagamune K, Acosta-Serrano A, Uemura H, et al. Surface sialic acids taken from the host allow trypanosome survival in tsetse fly vectors. J Exp Med 2004; 199: 1445-50.

[101] Engstler M, Schauer R, Brun R. Distribution of developmentally regulated trans-sialidases in the Kinetoplastida and characterization of a shed trans-sialidase activity from procyclic Trypanosoma congolense. Acta Trop 1995; 59: 117-29.

[102] Medina-Acosta E, Franco AMR, Jansen AM, et al. Trans-sialidase and sialidase activities discriminate between morphologically indistinguishable trypanosomatids. Eur J Biochem 1994; 225; 333-9.

[103] El-Sayed NMA, Donelson JE. African trypanosomes have differentially expressed genes encoding homologues of the Leishmania GP63 surface protease. J Biol Chem 1997; 272: 26742-748.

[104] Buschiazzo A, Tavares GA, Campetella O, et al. Structural basis of sialyltransferase activity in trypanosomal sialidases EMBO J 2000; 19(1): 16-24.

[105] Agusti R, Couto AS, Campetella OE, Frasch AC, de Lederkremer RM. The trans-sialidase of Trypanosoma cruzi is anchored by two different lipids. Glycobiology 1997; 6: 731-5.

[106] MacRae JI, Acosta-Serrano A, Morrice NA, Mehlert A, Ferguson MAJ. Structural Characterization of NETNES, a Novel Glycoconjugate in Trypanosoma cruzi epimastigotes J Biol Chem 2005; 280(13): 12201-11.

[107] Cuevas IC, Cazzulo JJ, Sánchez DO. gp63 Homologues in Trypanosoma cruzi: Surface Antigens with Metalloprotease Activity and a Possible Role in Host Cell Infection. Infect Immun 2003; 71: 5739-49.

[108] Blum ML, Down JA, Gurnett AM, Carrington M, Turner MJ, Wiley DC. A structural motif in the variant surface glycoproteins of Trypanosoma brucei. Nature 1993; 362: 603-9.

[109] Cross GA. Identification, purification and properties of clone specific glycoprotein antigens constituting the surface coat of Trypanosoma brucei. Parasitology 1975; 71: 393-417.

[110] Ferguson MAJ, Low MG, Cross G A. Glycosyl sn-1,2- dimyristylphosphatidylinositol is covalently linked to Trypanosoma brucei variant surface glycoprotein. J Biol Chem 1985; 260: 14547-55.

[111] Cardoso de Almeida ML, Turner MJ. The membrane form of variant surface glycoproteins of Trypanosoma brucei. Nature 1983; 302: 349- 52.

[112] Santos AL, Branquinha MH, D'Avila-Levy CM. The ubiquitous gp63-like metalloprotease from lower trypanosomatids: in the search for a function. An Acad Bras Cienc 2006; 78: 687-714.

[113] Santos AL, d'Avila-Levy CM, Elias CG, Vermelho AB, Branquinha MH. Phytomonas serpens: immunological similarities with the human trypanosomatid pathogens. Microbes Infect 2007; (8): 915-21.

[114] Yao C. Major Surface Protease (MSP, or GP63) of Trypanosomatids, One Size Fits All? Infect Immun 2010; 78(1): 22-31.

[115] Cross GA. Antigenic varition in trypanosomes: secrets surface slowly. Bioessays 1996; 18: 283-91.
[116] Mowatt MR, Clayton CE. Developmental regulation of a novel repetitive protein of Trypanosoma brucei. Mol Cell Biol 1987; 7: 2838-44.

[117] Roditi I, Carrington M, Turner M. Expression of a polypeptide containing a dipeptide repeat is confined to the insect stage of Trypanosoma brucei. Nature 1987; 325: 272-4.

[118] Lillico S, Field MC, Blundell P, Coombs GH, Mottram JC. Essential roles for GPI-anchored proteins in African trypanosomes revealed using mutants deficient in GPI8. Mol Biol Cell 2003; 14: 1182-94.

[119] Vassella E, Butikofer P, Engstler M, Jelk J, Roditi I. Procyclin null mutants of Trypanosoma brucei express free glycosylphosphatidylinositols on their surface. Mol Biol Cell 2003; 14: 1308-18.

[120] Treumann A, Zitzmann N, Hulsmeier A, et al. Structural characterisation of two forms of procyclic acidic repetitive protein expressed by procyclic forms of Trypanosoma brucei. J Mol Biol 1997; 269: 529-47.

[121] Richardson JP, Beecroft RP, Tolson DL, Liu MK, Pearson, TW Procyclin: an unusual immunodominant glycoprotein surface antigen from the procyclic stage of African trypanosomes. Mol Biochem Parasitol 1988; 31: 203-16.

[122] Güther ML, Beattie K, Lamont DJ, James J, Prescott AR, Ferguson MA. Fate of glycosylphosphatidylinositol (GPI)-less procyclin and characterization of sialylated non-GPI-anchored surface coat molecules of procyclic-form Trypanosoma brucei. Eukaryot Cell 2009; 8(9): 1407-17.

[123] Acosta-Serrano A, Vassella E, Liniger M, et al. The surface coat of procyclic Trypanosoma brucei: programmed expression and proteolytic cleavage of procyclinin the tsetse fly. Proc Natl Acad Sci USA 2001; 98: 1513-8.

[124] Ferguson MA, Homans SW, Dwek RA, Rademacher TW. Glycosyl-phosphatidylinositol moiety that anchors Trypanosoma brucei variant surface glycoprotein to the membrane. Science 1988; 239: 753-59.

[125] Bouvier J, Bordier C, Vogel H, Reichelt R, Etges RJ. Characterization of the promastigote surface protease of Leishmania as a membrane-bound zinc endopeptidases. Mol Biochem Parasitol 1989; 37: 235-45.

[126] Joshi PB, Kelly BL, Kamhawi S, Sacks DL, McMaster WR. Targeted gene deletion in Leishmania major identifies leishmanolysin (GP63) as a virulence factor. Mol Biochem Parasitol 2002; 120: 33-40.

[127] McGwire BS, O'Connell WA, Chang KP, Engman DM. Extracellular release of the glycosylphosphatidylinositol (GPI)-linked Leishmania surface metalloprotease, gp63, is independent of GPI phospholipolysis. J Biol Chem 2002; 277: 8802-09.

[128] Brittingham A, Morrison CJ, McMaster WR, McGwire BS, Chang KP, Mosser DM. Role of the Leishmania surface protease gp63 in complement fixation, cell adhesion, and resistance to complementmediated lysis. J Immunol 1995; 155: 3102-11.

[129] Kulkarni MM, McMaster WR, Kamysz E, Kamysz W, Engman DM, McGwire BS. The major surface-metalloprotease of the parasitic protozoan, Leishmania, protects against antimicrobial peptideinduced apoptotic killing. Mol Microbiol 2006; 62: 1484-97.

[130] Chaudhuri G, Chang KP. Acid protease activity of a major surface membrane glycoprotein (gp63) from Leishmania mexicana promastigotes. Mol Biochem Parasitol 1988; 27(1): 43-52.

[131] McGwire BS, Chang KP, Engman DM. Migration through the extracellular matrix by the parasitic protozoan Leishmania is enhanced by surface metalloprotease gp63. Infect Immun 2003; 71: 1008-10.

[132] Yao C, Donelson JE, Wilson ME. Internal and Surface-Localized Major Surface Proteases of Leishmania spp. and their differential release from promastigotes. Eukaryot Cell 2007; 6: 1905-12.

[133] Kulkarni MM, Jones EA, McMaster WR, McGwire BS. Fibronectin Binding and Proteolytic Degradation by Leishmania and Effects on Macrophage ActivationInfect Immun 2008; 76: 1738-47.

[134] Brittingham A, Chen G, McGwire BS, Chang KP, Mosser D. Interaction of Leishmania gp63 with cellular receptors for fibronectin. Infect Immun 1999; 67: 4477-84. 
[135] Rizvi FS, Ouaissi MA, Marty B, Santoro F, Capron A. The major surface protein of Leishmania promastigotes is a fibronectin-like molecule. Eur J Immunol 1988; 18(3): 473-6.

[136] Hallé M, Gomez MA, Stuible M, et al. The Leishmania Surface Protease GP63 Cleaves Multiple Intracellular Proteins and Actively Participates in p38 Mitogen-activated protein kinase Inactivation. J Biol Chem 2009; 284(11): 6893-69.

[137] Corradin S, Ransijn A, Corradin G, et al. MARCKS-related protein (MRP) is a substrate for the Leishmania major surface protease leishmanolysin (gp63). J Biol Chem 1999; 274: 25411-8.

[138] Gomez MA, Contreras I, Hallé M, Tremblay ML, McMaster RW, Olivier ML. Leishmania GP63 alters host signaling through cleav- age-activated protein tyrosine phosphatases. Sci Signal 2009; 2 (90): ra58.

[139] Zarei M, Müthing J, Peter-Katalinic J, Bindilla L. Separation and identification of GM1b pathway Neu5Ac- and Neu5Gc gangliosides by on-line nanoHPLC-QTof MS and tandem MS: toward glycolipidomics screening of animal cell lines. Glycobiology 2010; 20: $118-26$

[140] Gilson PR, Nebl T, Vukcevic D, et al. Identification and stoichiometry og glycosylphosphatidylinositol-anchores membrane proteins of the human malaria parasite Plasmodium falciparum. Mol Cell Proteomics 2006; 57: 1286- 98.

[141] Kamena F, Tamborrini M, Liu X, et al. Synthetic GPI array to study antitoxic malaria response. Nat Chem Biol 2008; 4: 238-40.

Received: February 28, 2010

(c) Barreto-Bergter and Vermelho; Licensee Bentham Open.

This is an open access article licensed under the terms of the Creative Commons Attribution Non-Commercial License (http://creativecommons.org/licenses/by-nc/3.0/) which permits unrestricted, non-commercial use, distribution and reproduction in any medium, provided the work is properly cited. 